\title{
Systematic review reporting guide
}

\section{Correspondence: ccdr-rmtc@phac-aspc.gc.ca}

Systematic reviews summarize the state of knowledge about a topic. They clarify both what is known and what needs further study and are used to stay up-to-date, to inform the development of advisory statements and clinical practice guidelines and to identify priorities for future research. They are typically $2,000-2,500$ words in length excluding the abstract, tables and references.

The Canada Communicable Disease Report (CCDR) endorses the widely-accepted reporting guideline, the Preferred Reporting Items of Systematic reviews and Meta-Analyses (PRISMA) (1). This guide was initially developed for health care interventions and has now been adapted for other uses $(2,3,4)$.

Table 1 provides the PRISMA checklist. Figure 1 illustrates a flow diagram that identifies how the initial number of studies identified during a literature search was pared down to the studies for review.

There are some additional considerations for systematic reviews on infectious disease topics. These include the need to consider differences across studies in laboratory methods used for the identification of infectious diseases, the presence or degree of antibiotic resistance and how case definitions were used to interpret laboratory results. Generic names are used to identify antibiotics or vaccines; brand names may be noted in brackets upon first use.

As with all submissions, check CCDR's Information for authors (published in January every year with the first issue of each new volume) for general manuscript preparation and submission requirements.

Table 1: PRISMA Checklist for systematic reviews

\begin{tabular}{|c|c|c|}
\hline Reporting item & $\mathbf{N}^{01}$ & Description \\
\hline \multicolumn{3}{|l|}{ Title } \\
\hline Title & 1 & Identify the report as a systematic review, meta-analysis or both. \\
\hline \multicolumn{3}{|l|}{ Abstract } \\
\hline Structured summary & 2 & $\begin{array}{l}\text { Provide a structured abstract including the following subheadings: } \\
\text { Background; Objectives; Data sources; Study selection; Synthesis; } \\
\text { Conclusions and, when applicable, systematic review registration } \\
\text { number. }\end{array}$ \\
\hline \multicolumn{3}{|l|}{ Introduction } \\
\hline Rationale & 3 & $\begin{array}{l}\text { Describe the rationale for the review in the context of what is already } \\
\text { known. }\end{array}$ \\
\hline Objectives & 4 & $\begin{array}{l}\text { Provide an explicit statement of questions being addressed with } \\
\text { reference to Participants, Interventions, Comparisons, Outcomes and } \\
\text { Study design (PICOS). }\end{array}$ \\
\hline \multicolumn{3}{|l|}{ Methods } \\
\hline $\begin{array}{l}\text { Protocol and } \\
\text { registration }\end{array}$ & 5 & $\begin{array}{l}\text { Indicate if a review protocol exists, if and where it can be accessed } \\
\text { (e.g., website address) and, if available, provide registration } \\
\text { information including registration number. }\end{array}$ \\
\hline Eligibility criteria & 6 & $\begin{array}{l}\text { Specify study characteristics (e.g., PICOS, length of follow-up) and } \\
\text { report characteristics (e.g., years considered, language, publication } \\
\text { status) used as criteria for eligibility, giving rationale. }\end{array}$ \\
\hline Information sources & 7 & $\begin{array}{l}\text { Describe all information sources (e.g., databases with dates of } \\
\text { coverage, contact with study authors to identify additional studies) in } \\
\text { the search and date last searched. }\end{array}$ \\
\hline
\end{tabular}




\begin{tabular}{|c|c|c|}
\hline Search & 8 & $\begin{array}{l}\text { Present full electronic search strategy for at least one database, } \\
\text { including any limits used, such that it could be repeated. }\end{array}$ \\
\hline Study selection & 9 & $\begin{array}{l}\text { State the process for selecting studies (e.g., screening, eligibility, } \\
\text { included in systematic review and, if applicable, included in the meta- } \\
\text { analysis). }\end{array}$ \\
\hline Data collection process & 10 & $\begin{array}{l}\text { Describe method of data extraction from reports (e.g., piloted forms, } \\
\text { independently, in duplicate) and any processes for obtaining and } \\
\text { confirming data from investigators. }\end{array}$ \\
\hline Data items & 11 & $\begin{array}{l}\text { List and define all variables for which data were sought (e.g., PICOS, } \\
\text { funding sources) and any assumptions and simplifications made. }\end{array}$ \\
\hline $\begin{array}{l}\text { Risk of bias in } \\
\text { individual studies }\end{array}$ & 12 & $\begin{array}{l}\text { Describe methods used for assessing risk of bias of individual studies } \\
\text { (including specification of whether this was done at the study or } \\
\text { outcome level) and how this information is to be used in any data } \\
\text { synthesis. }\end{array}$ \\
\hline Summary measures & 13 & $\begin{array}{l}\text { State the principal summary measures (e.g., risk ratio, difference in } \\
\text { means). }\end{array}$ \\
\hline Synthesis of results & 14 & $\begin{array}{l}\text { Describe the methods of handling data and combining results of } \\
\text { studies, if done, including measures of consistency (e.g., I2) for each } \\
\text { meta-analysis. }\end{array}$ \\
\hline $\begin{array}{l}\text { Risk of bias across } \\
\text { studies }\end{array}$ & 15 & $\begin{array}{l}\text { Specify any assessment of risk of bias that may affect the cumulative } \\
\text { evidence (e.g., publication bias, selective reporting within studies). }\end{array}$ \\
\hline Additional analyses & 16 & $\begin{array}{l}\text { Describe methods of additional analyses (e.g., sensitivity or subgroup } \\
\text { analyses, meta-regression) and if done, indicate which were pre- } \\
\text { specified. }\end{array}$ \\
\hline \multicolumn{3}{|l|}{ Results } \\
\hline Study selection & 17 & $\begin{array}{l}\text { Provide numbers of studies screened, assessed for eligibility and } \\
\text { included in the review, with reasons for exclusions at each stage, } \\
\text { ideally with a flow diagram. }\end{array}$ \\
\hline Study characteristics & 18 & $\begin{array}{l}\text { For each study, present characteristics for which data were extracted } \\
\text { (e.g., study size, PICOS, follow-up period) and provide the citations. }\end{array}$ \\
\hline $\begin{array}{l}\text { Risk of bias within } \\
\text { studies }\end{array}$ & 19 & $\begin{array}{l}\text { Present data on risk of bias of each study and, if available, any } \\
\text { outcome level assessment (see item 12). }\end{array}$ \\
\hline $\begin{array}{l}\text { Results of individual } \\
\text { studies }\end{array}$ & 20 & $\begin{array}{l}\text { For all outcomes considered (benefits or harms), present, for each } \\
\text { study: simple summary data for each intervention group and effect } \\
\text { estimates and confidence intervals, ideally with a forest plot. }\end{array}$ \\
\hline Synthesis of results & 21 & $\begin{array}{l}\text { Present the main results of the review. If meta-analyses are done, } \\
\text { include for each, confidence intervals and measures of consistency. }\end{array}$ \\
\hline $\begin{array}{l}\text { Risk of bias across } \\
\text { studies }\end{array}$ & 22 & $\begin{array}{l}\text { Present the results of any assessment of risk of bias across studies } \\
\text { (see Item 15). }\end{array}$ \\
\hline Additional analysis & 23 & $\begin{array}{l}\text { Provide the results of additional analyses, if done (e.g., sensitivity or } \\
\text { subgroup analyses, meta-regression [see Item 16]). }\end{array}$ \\
\hline \multicolumn{3}{|l|}{ Discussion } \\
\hline Summary of evidence & 24 & $\begin{array}{l}\text { Summarize the main findings including the strength of evidence for } \\
\text { each main outcome; consider their relevance to key groups (e.g., } \\
\text { healthcare providers, users and policy makers). }\end{array}$ \\
\hline Limitations & 25 & $\begin{array}{l}\text { Discuss limitations at study and outcome level (e.g., risk of bias) and } \\
\text { at review-level (e.g., incomplete retrieval of identified research, } \\
\text { reporting bias). }\end{array}$ \\
\hline
\end{tabular}




\begin{tabular}{|l|l|l|}
\hline Conclusions & 26 & $\begin{array}{l}\text { Provide a general interpretation of the results in the context of other } \\
\text { evidence and implications for future research. }\end{array}$ \\
\hline Funding & 27 & $\begin{array}{l}\text { Describe the sources of funding for the systematic review and other } \\
\text { support (e.g., supply of data) and role of funders for the systematic } \\
\text { review. }\end{array}$ \\
\hline Funding
\end{tabular}

${ }^{1} \mathrm{~N}^{\mathrm{O}}$ : Number

${ }^{2}$ Description of the abstract has been modified for the Canada Communicable Disease Report (CCDR).

${ }^{3}$ Reflects correction as noted on: http://www.prisma-statement.org/statement.htm.

Figure 1: PRISMA 2009 flow diagram

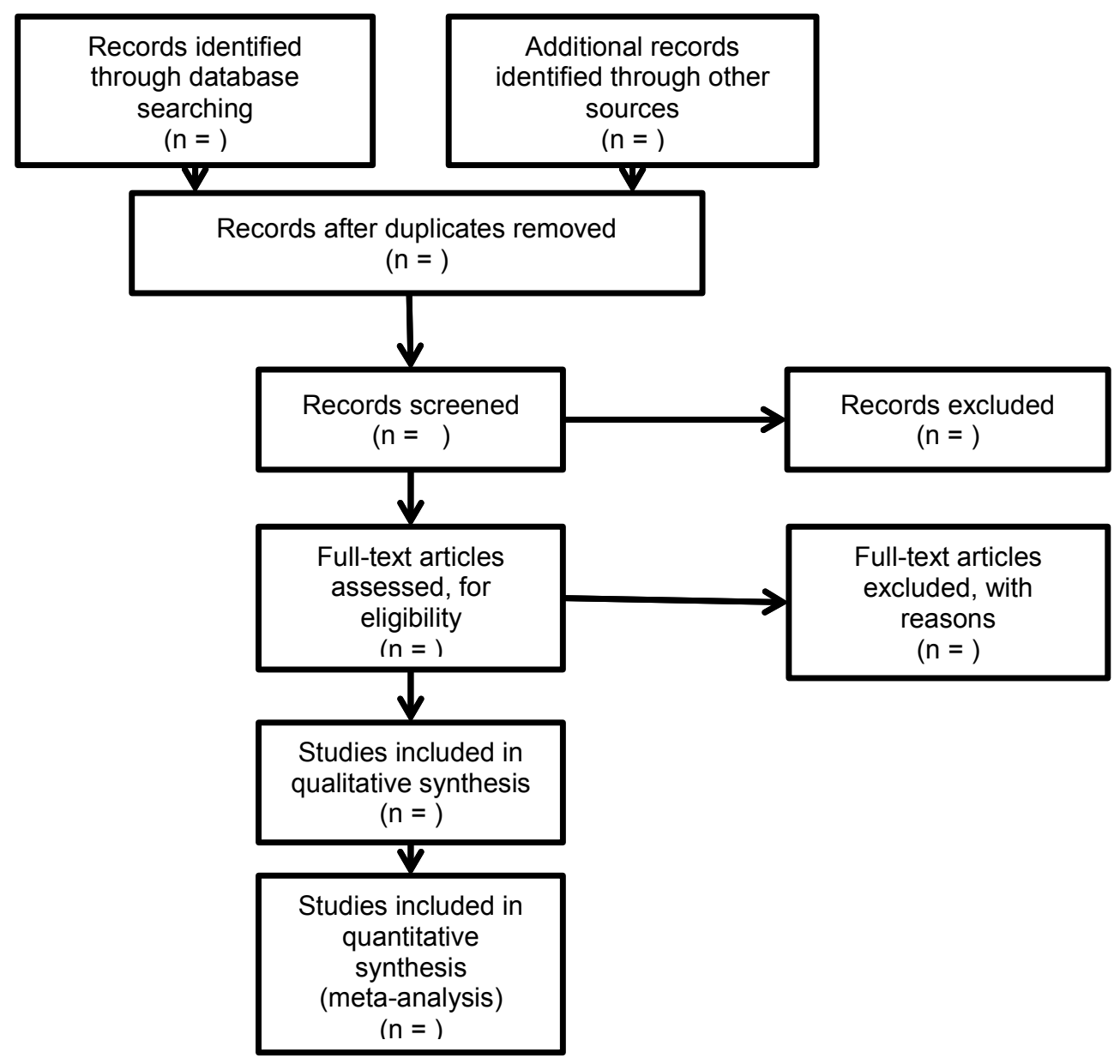




\section{References}

(1) Moher D, Liberati A, Tetzlaff J, Altman DG, for the PRISMA Group. Preferred reporting items for systematic reviews and meta-analyses: The PRISMA statement. BMJ. 2009;339:332-336.

(2) Welch V, Petticrew M, Tugwell P, Moher D, O'Neill J, Waters E, White H, PRISMA-Equity Bellagio Group. PRISMAequity 2012 extension: Reporting guidelines for systematic reviews with a focus on health equity. PLoS Med. 2012;9(10):e1001333.

(3) Beller EM, Glasziou PP, Altman DG, Hopewell S, Bastian H, Chalmers I, Gøtzsche PC, Lasserson T, Tovey D, PRISMA for Abstracts Group. PRISMA for abstracts: Reporting systematic reviews in journal and conference abstracts. PLoS Med. 2013;10(4):e1001419.

(4) Moher D, Shamseer L, Clarke M, Ghersi D, Liberati A, Petticrew M, Shekelle P, Stewart LA. Preferred reporting items for systematic review and meta-analysis protocols (PRISMA-P) 2015 statement. Syst Rev. 2015;4(1):1. 